\title{
Concurrent Resolution of Chronic Diarrhea Likely Due to Crohn's Disease and Infection with Mycobacterium avium paratuberculosis
}

\author{
Shoor V. Singh ${ }^{1}$, J. Todd Kuenstner ${ }^{2}$, William C. Davis ${ }^{3 *}$, Prabhat Agarwal ${ }^{4}$, Naveen Kumar', \\ Devendra Singh ${ }^{5}$, Saurabh Gupta ${ }^{1}$, Kundan K. Chaubey ${ }^{1}$, Ashok Kumar ${ }^{6}$, Jyoti Misri', \\ Sujatha Jayaraman ${ }^{7}$, Jagdip S. Sohal ${ }^{7}$ and Kuldeep Dhama ${ }^{8}$ \\ ${ }^{1}$ Microbiology Laboratory, Animal Health Division, Central Institute for Research on Goats, Mathura, India, ${ }^{2}$ Temple University \\ Hospital, Philadelphia, PA, USA, ${ }^{3}$ Microbiology and Pathology, Washington State University, Pullman, WA, USA, \\ ${ }^{4}$ Department of Medicine, S.N. Medical College, Agra, India, ${ }^{5}$ State Animal Husbandry Department, Kumher, India, ${ }^{6}$ Division \\ of Animal Science, Krishi Bhavan (ICAR), New Delhi, India, ${ }^{7}$ Amity Institute of Microbial Technology, Amity University Jaipur, \\ Jaipur, India, ${ }^{8}$ Department of Pathology, Indian Veterinary Research Institute, Bareilly, India
}

OPEN ACCESS

Edited by:

Arun Chaudhury,

GIM Foundation, USA

Reviewed by:

Chitharanjan Duvoor,

University of Arkansas for Medical

Sciences, USA

Chaitanya K. Musham,

St. Vincent Infirmary, USA

Nawal Singh Shekhawat,

Tutwiler Clinic, USA

Asween Marco,

University of Arkansas

Little Rock, USA

*Correspondence:

William C. Davis

davisw@vetmed.wsu.edu

Specialty section:

This article was submitted

to Gastroenterology,

a section of the journal

Frontiers in Medicine

Received: 04 August 2016

Accepted: 11 October 2016

Published: 27 October 2016

Citation:

Singh SV, Kuenstner JT, Davis WC, Agarwal P, Kumar N, Singh D, Gupta S, Chaubey KK, Kumar A, Misri J, Jayaraman S, Sohal JS and Dhama K (2016) Concurrent Resolution of Chronic Diarrhea Likely Due to Crohn's

Disease and Infection with

Mycobacterium avium paratuberculosis.

Front. Med. 3:49

doi: 10.3389/fmed.2016.00049
Examination of samples of stool from a 61-year-old male patient, presenting with the clinical symptoms of Crohn's disease (CD), revealed massive shedding of acid fast bacilli with the morphology of Mycobacterium avium paratuberculosis (MAP), the causative agent of Johne's disease in cattle. MAP was cultured from the stool. Biotyping of the bacterium isolated from cultures of stool demonstrated, it was the Indian Bison biotype of MAP, the dominant biotype infecting livestock and humans in India. Based on this finding and because the patient was unresponsive to standard therapy used in India to treat patients with gastrointestinal inflammatory disorders, the patient was placed on a regimen of multi-antibiotic therapy, currently used to treat tuberculosis and CD. After 1 year of treatment, the patient's health was restored, concurrent with cessation of shedding of MAP in his stool. This patient is the first case shown to shed MAP from the stool who was cured of infection with antibiotics and who was concurrently cured of clinical signs of CD.

Keywords: Mycobacterium avium paratuberculosis, Crohn's disease, antibiotic therapy, stool culture and microscopy for MAP, ELISA, IS900 PCR and IS1311 PCR_RE

\section{INTRODUCTION}

A major question that has remained unanswered over the past years is whether Mycobacterium avium paratuberculosis $(M A P)$, the causative agent of Johne's disease in cattle, is zoonotic and also the causative agent of Crohn's disease (CD). The lack of resolution of this question is partly attributable to the difficulty of demonstrating the presence of MAP in all patients with the clinical symptoms of $\mathrm{CD}$ and the finding of MAP in patients with other gastrointestinal disorders as well as other diseases and also in humans with no signs of disease. The case report presented here, and results from an extensive survey we recently conducted in India, have provided an explanation for why it has been difficult to show $M A P$ is the causative agent of $C D$ in, at least, a subset of patients with $C D$. The survey of 42,400 subjects revealed humans like other species are equally susceptible to infection with MAP regardless of health status (1). We detected the presence of $M A P$ in subjects with no clinical signs of disease and subjects with disorders involving the skin, liver, abdomen, gastrointestinal tract, thyroid, 
blood (anemia), pancreas (diabetes), autoimmune inflammatory disorders, and infectious diseases, e.g., tuberculosis, typhoid, and malaria. The survey also revealed very few of subjects infected with MAP had detectable cocco-bacilli in their stool, as detected by microscopy, including subjects with overt clinical signs of CD, similar to an earlier study (2). The subjects identified in these studies were poor, and there was no opportunity to arrange for treatment, leaving open the question of whether antibiotic therapy could be used to cure infection with $M A P$ and whether a cure would also affect a cure of CD. The subject of this case report has provided an opportunity to answer both questions.

\section{CASE REPORT}

A 61-year-old male, a resident of a rural village of Rajasthan state in India, had a history of frequent bowel movements with passage of loose stool or mucus every half hour. He had lost weight and was emotionally distressed by the lack of the medical community's ability to obtain a diagnosis and treatment for his illness. The patient was referred to us at the Central Institute for Goat Research (CIRG) approximately 3 years ago by his relative, a veterinary officer in the State Animal Husbandry Department of Rajasthan state. The officer was familiar with the screening of animals for MAP infection in goats, sheep, cattle, and buffaloes and knew of the reported association of MAP with CD. On the initial visit, the patient suffered from severe depression in addition to presenting with the clinical signs and symptoms of diarrhea, weakness, weight loss, fatigue, and anorexia, symptoms that closely resemble the clinical symptoms of Johne's disease in cattle, except for anorexia [reviewed in Ref. (3)]. At the clinical stage of Johne's disease, there is extensive infiltration of the mucosa with MAP infected macrophages and lymphocytes, associated with a loss in the integrity of the absorptive epithelium, resulting weight loss, and constant diarrhea. Bacteria are readily identified in feces at this late stage of disease [reviewed in Ref. (3)]. The patient was desperate and turned to the CIRG as a last resort. The patient had consulted with gastroenterologists over the previous years and sought care in hospitals in Bharatpur and New Delhi (Aakash Medical Center, Sir Ganga Ram Hospital and All India Institute of Medical Sciences) for the treatment of his ailment. Several endoscopic evaluations conducted during the visits to hospitals demonstrated the presence of inflammation in the intestine (Figure 1); however, the gastroenterologists did not include CD as one of the possible reasons for inflammation. Biopsies were not taken for evaluation. The patient was treated with the standard therapy for Irritable bowel diarrhea (IBD), steroids, and azathioprine. Treatment provided no improvement.

Serum, blood, and stool were collected to check for the presence of MAP infection, using the four diagnostic tests [microscopy, culture, IS900 PCR (stool and blood), and ELISA] used in the survey $(1,4)$. The general procedure for isolating MAP for culture and examination by microscopy in our laboratory proved to be exceptionally important with this case. The procedure for screening for the presence of MAP in fecal samples (2) is included in this report so that this procedure may be used by other laboratories. Approximately $2 \mathrm{~g}$ of stool were placed in $12 \mathrm{ml}$ of sterilized water and finely minced using a pestle and mortar under sterilized

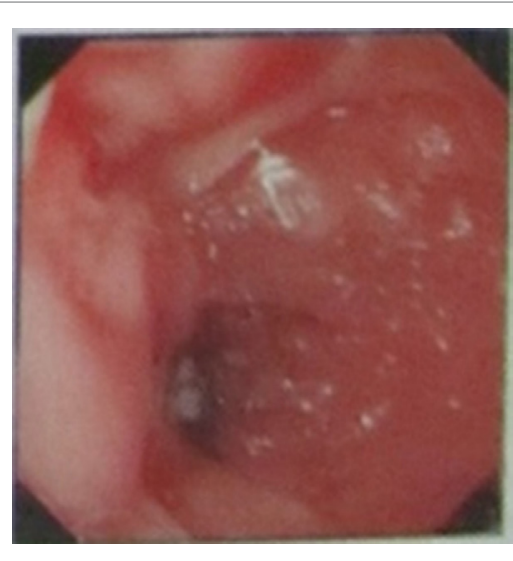

FIGURE 1 | Representative picture showing results from three independent endoscopic evaluations of the intestine of the patient obtained at different times before he was started on antibiotic therapy. There was no opportunity for further evaluations during treatment.

conditions. The mixture was then centrifuged at $4,500 \mathrm{rpm}$ at room temperature for $45 \mathrm{~min}$. The supernatant was discarded, leaving a pellet, comprised of a dense layer of solid material at the bottom and a thin layer of semisolid less dense material at the top. Two sterile swabs were used to collect material from the semisolid upper layer, one to make a slide and the second to prepare a culture. The latter swab was placed in a tube containing $40 \mathrm{ml}$ of a $0.9 \%$ hexadecyl pyridinium chloride in water to decontaminate fecal material. The mixture was allowed to stand for $18 \mathrm{~h}$ at room temperature. The supernatant was decanted and $0.2 \mathrm{ml}$ of the residual sediment inoculated onto slants of Herrold's egg yolk medium (three containing mycobactin J and one without mycobactin J). Microscopic examination of the stool specimen revealed the patient was shedding massive numbers of acid fast short rods (cocco-bacilli) ( +3 to +4$)$, with morphology indistinguishable from MAP (Figure 2A). Following 5 months of culture of stool, small colonies of bacteria were detected in agar slants containing mycobactin J. Biotyping of the colonies with the IS 1311 PCR_RE and IS1311 L2 PCR_REA $(5,6)$ demonstrated the bacterium was the "Indian Bison type," of MAP, the prevalent form of MAP in India (4). The patient's serum was positive for $M A P$ by ELISA.

\section{TREATMENT}

After our report to the patient, the patient went to New Delhi to the All India Institute of Medical Sciences, which is one of the best institutions in Medicine in India. He met with the Head of the Division of Gastroenterology for treatment. The gastroenterologist believed the patient had IBD and treated him accordingly with the standard treatment for IBD. Following 15 days of treatment, there was no improvement in the patient's failing condition and he returned to the CIRG very depressed. He was losing weight with the frequency of bowel movements every half hour. He requested the CIRG provide him with an injection of institute's vaccine that was shown to have a therapeutic effect. He was informed that this was not possible. As an alternative, 

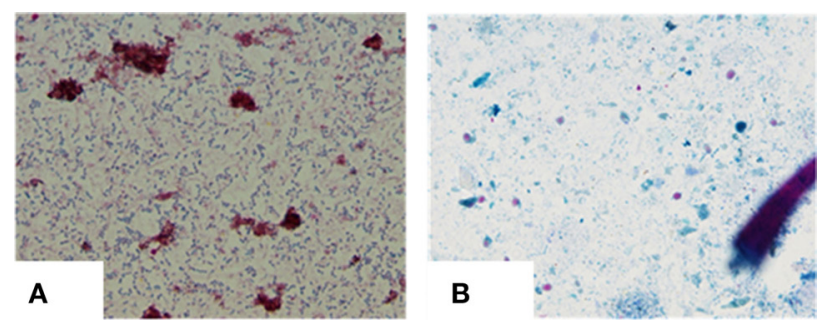

FIGURE 2 | (A) Heavy shedding of typical MAP bacilli as seen in ZN staining: 4+ (positive). (B) Negative for MAP bacilli at the end of 12 months of treatment.

we at CIRG arranged for consultation with a local physician and coauthor, Dr. Prabhat Agarwal, an Assistant Professor at the S.N. Medical College, Agra, with a small clinic in Farah where CIRG is located. Dr. Prabhat Agarwal took interest in the case and was willing to consider the patient's illness could be associated with an extensive infection with MAP. Dr. T. J. Borody, who had reported success in treating patients with $C D$ with antibiotics was contacted for advice and recommendation on how to treat the patient (7). Dr. Borody provided copies of recent publications and suggested what antibiotics should be considered for treatment. Based on his suggestions, a regimen of therapy was designed and implemented. The patient was informed that his clinical symptoms were most likely caused by a MAP infection and that a regimen of antibiotic therapy might provide a cure. After obtaining his written consent, he was placed on anti-MAP therapy under the supervision of Dr. Prabhat Agarwal. The antibiotic therapy included clarithromycin, rifampin, ethambutol, levofloxacin, isoniazid, and rifaximin along with mesalazine according to the schedule in Table $\mathbf{1 .}$

\section{RESULTS}

After 4 months of treatment, the patient exhibited improvement in his physical condition, reduction in stool frequency (two to three times a day from every half hour), and improvement in appetite. During the last months of treatment, the patient experienced continued improvement, with an increase in weight and further reduction in stool frequency (one to two times a day). Recovery from infection was complete following a year of treatment with no signs or symptoms of disease. The follow-up stool microscopy was negative for MAP (Figure 2B) and the follow-up post-treatment stool culture was negative for MAP. As mentioned, biotyping of colonies from cultures of stool showed the bacilli were the "Indian Bison type" of MAP (Figure 3). The ELISA was positive for $M A P$ also, further confirmation that the patient had been infected with MAP (Table 2). The patient is now being monitored every 6 months for recurrence of infection and general health.

\section{DISCUSSION}

Recent studies have shown that humans like other species are susceptible to infection with MAP. The first evidence
TABLE 1 | Summary of treatment regimen up to 12 months.

\begin{tabular}{lll}
\hline Drug categories & Type of medicine & Treatment duration \\
\hline Antibiotics & Levofloxacin $(750 \mathrm{mg})$ & 1-11 weeks \\
& Clarithromycin $(250 \mathrm{mg})$ & 9-38 weeks \\
& Isoniazid $(300 \mathrm{mg})$ & Up to 13 weeks \\
& Rifampicin $(450 \mathrm{mg})$ & Up to 13 weeks \\
& Ethambutol $(800 \mathrm{mg})$ & Up to 13 weeks \\
& Rifaximin $(550 \mathrm{mg})$ & $7-18$ weeks \\
Anti-inflammatory & Rifabutin $(150 \mathrm{mg})$ & $11-42$ weeks \\
& Mesalazine or & $1-38$ weeks $(1 \mathrm{~g})$ and up \\
& 5-aminosalicylic acid & to 48 weeks $(2 \mathrm{~g})$
\end{tabular}

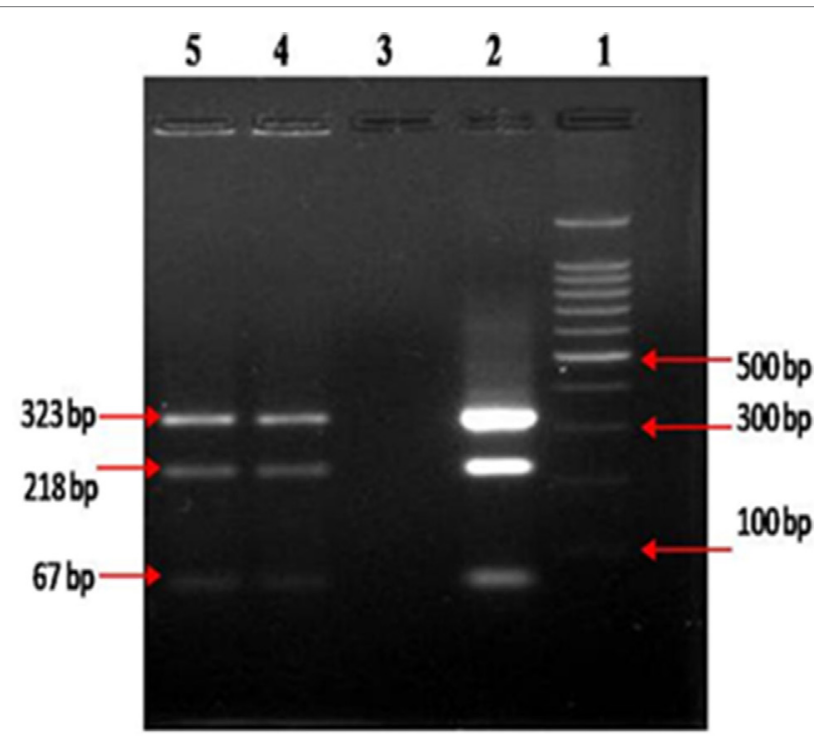

FIGURE 3 | Biotyping of "Indian Bison type" MAP bacilli, by IS 1311 PCR_REA, from colonies developed at the end of 12 months of culture on HEY medium, columns 4 and 5 .

TABLE 2 | Screening of clinical samples (feces, blood, and serum) by multiple diagnostic tests for the presence of MAP infection at different days post-treatment.

\begin{tabular}{lccc}
\hline Tests & 0th day & 120 days & 360 days \\
\hline 1. ELISA kit - serum & & & \\
a. OD values & & & \\
b. Status of MAP & 0.3255 & 0.7186 & 0.5826 \\
2. Microscopy - stool & Negative & Positive & Positive \\
3. Culture - stool & +3 to +4 & +2 to +1 & Negative \\
4. IS900 PCR-blood and stool & Multi-bacillary & Pauci-billary & Negative \\
& Negative & Negative & Negative
\end{tabular}

"Status of MAP infection as per S/P ratio (8) using "Indigenous ELISA kit."

${ }^{\circ} \mathrm{MAP}$ colonies took 1 year to grow.

${ }^{c}$ From DNA isolated directly from blood and stool samples.

of susceptibility was obtained in studies demonstrating the presence of MAP in healthy subjects and patients with various diseases used as controls in the study of CD (2, 9-16). Most of these studies involved examination of small numbers of individuals, at a time when it was technically difficult to isolate $M A P$ from tissues and fecal samples. Because it was thought that $M A P$ is not pathogenic for humans, patients were not routinely 
tested for an infection with MAP. Our recent extensive survey of 42,400 individuals for the presence of $M A P$, across the social spectrum of populations living in India, a country where there is a high prevalence of MAP in domestic and wild animals, the food supply and environment, has documented that humans, regardless of health status and position in society, can be infected with $M A P(1,17-19)$.

Genomic studies documented that animals and humans were infected with a single biotype, the Bison biotype, the most prevalent biotype in India, with a signatory short single repeat (SSR), $7 \mathrm{~g} 4 \mathrm{ggt}$, also found in the first isolates of MAP from humans in the United States of America (20). In addition to healthy subjects, the survey included patients with various illnesses, especially patients with intestinal disorders including $\operatorname{CD}(1,2)$. Assays developed to test for infection in domestic animals were used to screen subjects for the presence of MAP (21). The microscopic assay of fecal samples was the most expedient way to identify subjects clearly shedding bacteria indistinguishable from MAP. In contrast to other studies, bacteria indistinguishable from $M A P$ were detected in fecal samples of some patients with the clinical symptoms of CD. Follow-up assays with ELISA, culture, PCR with IS900, and biotyping of MAP colonies, using the IS1311 PCR_REA and IS1311 L2 PCR_REA method $(5,22)$, documented the isolates were the Indian Bison biotype of $\operatorname{MAP}(21,23,24)$. The survey also revealed that the bacterial load in stool was too low to be routinely detected by microscopy but could be detected by stool culture and specificity documented by IS900 PCR. A similar finding has been reported by a group of investigators in Italy (16).

The patient described in this report was from a small village in a rural region of Rajasthan state. Although it is not known how he became infected, MAP is endemic in livestock and the environment in this region. In this setting, exposure of the entire population could be from the contaminated environment, direct contact with livestock, or from the consumption of milk or milk products. Farmer families in India maintain a close contact with the domestic livestock, especially milking cattle, buffaloes, and goats, and often share living space with animals due to limited socioeconomic conditions. Studies on the bio-burden and biotyping of MAP infection in large populations of domestic livestock, wild ruminants, and other animals in the past 29 years have shown that MAP is widely prevalent and endemic in the domestic livestock population of the country $(4,19)$. In addition, as mentioned previously, mass screening of the human population in this part of India revealed a high level $(>30.0 \%)$

\section{REFERENCES}

1. Singh SV, Kumar N, Sohal JS, Singh AV, Singh PK, Agrawal ND, et al. First mass screening of the human population to estimate the bio-load of Mycobacterium avium sub-species paratuberculosis in North India. J Public Health Epidemiol (2014) 6:20-9. doi:10.5897/JPHE2013.0564

2. Singh AV, Singh SV, Makharia GK, Singh PK, Sohal JS. Presence and characterization of Mycobacterium avium subspecies paratuberculosis from clinical and suspected cases of Crohn's disease and in the healthy human population in India. Int J Infect Dis (2008) 12:190-7. doi:10.1016/j.ijid.2007.06.008

3. Rideout BA, Brown ST, Davis WC, Gay JM, Giannella RA, Hines ME, et al. Diagnosis and Control of Johne's Disease. Washington, DC: The National Academy Press (2003). of infection with MAP (1). Screening of milk and milk products also revealed a high bio-presence of $M A P$ (18). Biotyping of $M A P$ strains has consistently shown the presence of the dominant Indian Bison biotype as the most prevalent biotype of MAP detected in humans $(4,19)$.

As stated previously, one of the reasons why it has been so difficult to establish that $M A P$ is the causative agent of $C D$ in, at least, a subset of patients with $\mathrm{CD}$ has been that MAP has not been isolated from all patients. Also, the potential remains that more than one disease presents with the clinical features of $\mathrm{CD}$. A recent study by Chiodini et al. has reported that, "CD may be differentiated into 2 distinct biotypes, based on the detection of bacterial genomic sequences and virulence genes within submucosal tissues" (25). This case provides additional evidence, supporting studies showing MAP is the causative agent in, at least, a subset of patients with CD (26) and that antibiotic therapy may lead to a cure of CD and clearance of infection with $M A P$. The results are consistent with findings from a group of $M A P$ infected patients treated successfully by one of the coauthors, Dr. J. Todd Kuenstner, in the United States using a regimen of multi-antibiotic therapy combined with ultraviolet blood irradiation (UVBI) $(27,28)$. Of major importance, the results obtained in this report and the mass survey in India emphasize the need for recognition, at the international level, that MAP is a zoonotic pathogen and that it is a health risk for humans and livestock (29).

\section{INFORMED CONSENT}

Written informed consent was obtained from the patient for treatment and for publication of this report and accompanying images.

\section{AUTHOR CONTRIBUTIONS}

SS, JK, WD, and JM designed and helped write the report; PA performed the treatment; KD and AT analyzed the ethical and public health study; DS and SJ collected the patient's clinical data; and NK, JS, SG, and KC analyzed the data and wrote the paper.

\section{FUNDING}

Supported by Indian Council of Agricultural Research, New Delhi, India.

4. Singh SV, Sohal JS, Singh PK, Singh AV. Genotype profiles of Mycobacterium avium subspecies paratuberculosis isolates recovered from animals, commercial milk, and human beings in North India. Int J Infect Dis (2009) 13:e221-7. doi:10.1016/j.ijid.2008.11.022

5. Whittington RJ, Marsh IB, Whitlock RH. Typing of IS 1311 polymorphisms confirms that bison (Bison bison) with paratuberculosis in Montana are infected with a strain of Mycobacterium avium subsp. paratuberculosis distinct from that occurring in cattle and other domesticated livestock. Mol Cell Probes (2001) 15:139-45. doi:10.1006/mcpr.2001.0346

6. Singh AV, Chauhan DS, Singh A, Singh PK, Sohal JS, Singh SV. Application of IS1311 locus 2 PCR-REA assay for the specific detection of 'Bison type' Mycobacterium avium subspecies paratuberculosis isolates of Indian origin. Indian J Med Res (2015) 141:55-61. doi:10.4103/0971-5916.154497 
7. Borody TJ, Leis S, Warren EF, Surace R. Treatment of severe Crohn's disease using antimycobacterial triple therapy-approaching a cure? Dig Liver Dis (2002) 34:29-38. doi:10.1016/S1590-8658(02)80056-1

8. Collins MT. Interpretation of a commercial bovine paratuberculosis enzymelinked immunosorbent assay by using likelihood ratios. Clin Diagn Lab Immunol (2002) 9:1367-71. doi:10.1128/CDLI.9.6.1367-1371.2002

9. Bull TJ, Mcminn EJ, Sidi-Boumedine K, Skull A, Durkin D, Neild P, et al. Detection and verification of Mycobacterium avium subsp. paratuberculosis in fresh ileocolonic mucosal biopsy specimens from individuals with and without Crohn's disease. J Clin Microbiol (2003) 41:2915-23. doi:10.1128/ JCM.41.7.2915-2923.2003

10. Autschbach F, Eisold S, Hinz U, Zinser S, Linnebacher M, Giese T, et al. High prevalence of Mycobacterium avium subspecies paratuberculosis IS900 DNA in gut tissues from individuals with Crohn's disease. Gut (2005) 54:944-9. doi:10.1136/gut.2004.045526

11. Chiappini E, De Martino M, Mangiantini F, Lionetti P. Crohn's disease and mycobacterial infection in children: an intriguing relationship. J Pediatr Gastroenterol Nutr (2009) 49:550-8. doi:10.1097/MPG.0b013e3181b0f908

12. Juste RA, Elguezabal N, Pavón A, Garrido JM, Geijo M, Sevilla I, et al. Association between Mycobacterium avium subsp. paratuberculosis DNA in blood and cellular and humoral immune response in inflammatory bowel disease patients and controls. Int J Infect Dis (2009) 13:247-54. doi:10.1016/j. ijid.2008.06.034

13. Kirkwood CD, Wagner J, Boniface K, Vaughn J, Michalski WP, CattoSmith A, et al. Mycobacterium avium subspecies paratuberculosis in children with early-onset Crohn's disease. Inflamm Bowel Dis (2009) 15:1643-55. doi:10.1002/ibd.20967

14. Mendoza JL, San-Pedro A, Culebras E, Cies R, Taxonera C, Lana R, et al. High prevalence of viable Mycobacterium avium subspecies paratuberculosis in Crohn's disease. World J Gastroenterol (2010) 16:4558-63. doi:10.3748/wjg. v16.i36.4558

15. Lee A, Griffiths TA, Parab RS, King RK, Dubinsky MC, Urbanski SJ, et al. Association of Mycobacterium avium subspecies paratuberculosis with Crohn's disease in pediatric patients. J Pediatr Gastroenterol Nutr (2011) 52(2):170-4. doi:10.1097/MPG.0b013e3181ef37ba

16. Tuci A, Tonon F, Castellani L, Sartini A, Roda G, Marocchi M, et al. Fecal detection of Mycobacterium avium paratuberculosis using the IS900 DNA sequence in Crohn's disease and ulcerative colitis patients and healthy subjects. Dig Dis Sci (2011) 56:2957-62. doi:10.1007/s10620-011-1699-6

17. Kumar S, Singh SV, Singh AV, Singh PK, Sohal JS, Maitra A. Wildlife (Boselaphus tragocamelus)-small ruminant (goat and sheep) interface in the transmission of 'Bison type' genotype of Mycobacterium avium subspecies paratuberculosis in India. Comp Immunol Microbiol Infect Dis (2010) 33:145-59. doi:10.1016/j. cimid.2008.08.006

18. Shankar H, Singh SV, Singh PK, Singh AV, Sohal JS, Greenstein RJ. Presence, characterization, and genotype profiles of Mycobacterium avium subspecies paratuberculosis from unpasteurized individual and pooled milk, commercial pasteurized milk, and milk products in India by culture, PCR, and PCR-REA methods. Int J Infect Dis (2010) 14:e121-6. doi:10.1016/j.ijid. 2009.03.031

19. Singh SV, Singh PK, Singh AV, Sohal JS, Kumar N, Chaubey KK, et al. 'Bio-load' and bio-type profiles of Mycobacterium avium subspecies paratuberculosis infection in the domestic livestock population endemic for Johne's disease: a survey of 28 years (1985-2013) in India. Transbound Emerg Dis (2014) 61(Suppl 1):43-55. doi:10.1111/tbed.12216

20. Ghadiali AH, Strother M, Naser SA, Manning EJB, Sreevatsan S. Mycobacterium avium subsp. paratuberculosis strains isolated from Crohn's disease patients and animal species exhibit similar polymorphic locus patterns. J Clin Microbiol (2004) 42:5345-8. doi:10.1128/JCM.42.11.5345-5348.2004

21. Singh AV, Singh SV, Sohal JS, Singh PK. Genotype profiles of Mycobacterium avium subspecies paratuberculosis recovered from suspected and Crohn's disease patients in India. J Commun Dis (2010) 42:91-100.

22. Sevilla I, Singh SV, Garrido JM, Aduriz G, Rodriguez S, Geijo MV, et al. Molecular typing of Mycobacterium avium subspecies paratuberculosis strains from different hosts and regions. Rev Sci Tech (2005) 24:1061-6.

23. Sohal JS, Sheoran N, Narayanasamy K, Brahmachari V, Singh S, Subodh S. Genomic analysis of local isolate of Mycobacterium avium subspecies paratuberculosis. Vet Microbiol (2009) 134:375-82. doi:10.1016/j.vetmic. 2008.08.027

24. Singh AV, Singh SV, Singh PK, Sohal JS. Genotype diversity in Indian isolates of Mycobacterium avium subspecies paratuberculosis recovered from domestic and wild ruminants from different agro-climatic regions. Comp Immunol Microbiol Infect Dis (2010) 33:e127-31. doi:10.1016/j.cimid. 2010.08.001

25. Chiodini RJ, Dowd SE, Davis B, Galandiuk S, Chamberlin WM, Kuenstner JT, et al. Crohn's disease may be differentiated into 2 distinct biotypes based on the detection of bacterial genomic sequences and virulence genes within submucosal tissues. JClin Gastroenterol (2013) 47:612-20. doi:10.1097/ MCG.0b013e31827b4f94

26. Naser SA, Sagramsingh SR, Naser AS, Thanigachalam S. Mycobacterium avium subspecies paratuberculosis causes Crohn's disease in some inflammatory bowel disease patients. World J Gastroenterol (2014) 20:7403-15. doi:10.3748/ wjg.v20.i23.7403

27. Kuenstner JT, Chamberlin W, Naser SA, Collins MT, Dow CT, Aitken JM, et al. Resolution of Crohn's disease and complex regional pain syndrome following treatment of paratuberculosis. World J Gastroenterol (2015) 21:4048-62. doi:10.3748/wjg.v21.i13.4048

28. Kuenstner JT, Mukherjee S, Weg S, Landry T, Petrie T. The treatment of infectious disease with a medical device: results of a clinical trial of ultraviolet blood irradiation (UVBI) in patients with hepatitis C infection. Int J Infect Dis (2015) 37:58-63. doi:10.1016/j.ijid.2015.06.006

29. Davis WC. On deaf ears, Mycobacterium avium paratuberculosis in pathogenesis Crohn's and other diseases. World J Gastroenterol (2015) 21:13411-7. doi:10.3748/wjg.v21.i48.13411

Conflict of Interest Statement: The authors declare there were no financial or commercial conflicts of interest associated with the report of the present study.

Copyright (c) 2016 Singh, Kuenstner, Davis, Agarwal, Kumar, Singh, Gupta, Chaubey, Kumar, Misri, Jayaraman, Sohal and Dhama. This is an open-access article distributed under the terms of the Creative Commons Attribution License (CC BY). The use, distribution or reproduction in other forums is permitted, provided the original author(s) or licensor are credited and that the original publication in this journal is cited, in accordance with accepted academic practice. No use, distribution or reproduction is permitted which does not comply with these terms. 